\title{
IMPACTO DEL COVID 19 EN EL TURISMO URBANO DEL ECUADOR
}

\author{
Impact of COVID 19 on urban tourism in Ecuador
}

\author{
Carlos Garrido \\ Universidad Central del Ecuador y Universidad Internacional del Ecuador \\ crgarrido@uce.edu.ec \\ https://orcid.org/0000-0002-6673-5048
}

\section{Edison Molina}

Universidad Central del Ecuador emolina@uce.edu.ec https://orcid.org/0000-0001-7702-5079

RESUMEN: El objetivo de esta investigación fue realizar una evaluación del impacto que tuvo el Covid-19 en los diversos sectores del turismo ecuatoriano, teniendo un énfasis en la caracterización de ese impacto en el turismo urbano. Para ello se han sistematizado varias investigaciones que los autores realizaron durante el 2020, tanto en la empresa, el talento humano y la demanda turística nacional. Entre los principales resultados se encontró que un $13 \%$ de los establecimientos turísticos cerraron definitivamente su operación; y de manera sorpresiva se registró en 2020 un incremento en la apertura de establecimientos vinculados al alojamiento, centros de turismo comunitario y empresas de operación e intermediación turística. Es por tanto un reto de trabajo conjunto el levantar el turismo en el país, para lo cual los autores ven como única posibilidad un pacto de los actores para diseñar e implementar un plan urgente para salvar empleos, empresas y la cadena de valor del turismo en el país.

Palabras Clave: turismo, Ecuador, COVID 19, impactos, reactivación. 
RESUM: L'objectiu d'aquesta investigació va ser realitzar una avaluació de l'impacte que va tindre el Covid-19 en els diversos sectors del turisme equatorià, fent èmfasi en la caracterització d'aqueix impacte en el turisme urbà. Per a això s'han sistematitzat diverses investigacions que els autors van realitzar durant el 2020, tant enl'àmbit de l'empresa, el talent humà i la demanda turística nacional. Entre els principals resultats es va trobar que un $13 \%$ dels establiments turístics van tancar definitivament la seua operació; i de manera sorprenent es va registrar en 2020 un increment en l'obertura d'establiments vinculats a l'allotjament, centres de turisme comunitari i empreses d'operació i intermediació turística. És, per tant, un repte de treball conjunt l'alçar el turisme al país, per a assolir-ho els autors veuen com a única possibilitat un pacte dels actors per a dissenyar i implementar un pla urgent per a salvar ocupacions, empreses i la cadena de valor del turisme al país.

Paraules Clau: turisme, l'Equador, COVID-19, impactes, reactivació.

ABSTRACT: This article evaluates the impact of COVID on urban tourism in Ecuador through a systematic analysis of several studies carried out by the authors during 2020 into companies, human talent and the demand for domestic tourism. The problems facing the tourism sector in Ecuador are very serious and complex, not only in terms of the economy and job losses, but also due to the absence of any public reactivation plan that goes beyond good intentions. 2021 is a year of presidential elections, which will also impact on the possible reactivation of the sector. The authors argue that the challenge of stimulating recovery in the country's tourism sector can only be met by reaching an agreement among all stakeholders to design and implement an urgent plan to save jobs, companies and the tourism value chain in the country.

KeYwords: Tourism, Ecuador, COVID 19, impacts, reactivation 


\section{Introducción y estado de la cuestión}

\section{I.I. Impacto del COVID 19 en el turismo mundial}

n los últimos veinte años, el sector turístico a nivel global logró un
crecimiento inédito pasando a ser el primer sector en generación de empleo y divisas. Según la Organización Mundial de Turismo (OMT), para el año 2019 el turismo aportaba algo más del 10\% del PIB mundial, con cerca 1.7 billones de dólares generados por cerca de mil quinientos millones de turistas para el mismo año (OMT, 2019) siendo su décimo año consecutivo de crecimiento sostenido y convirtiéndose en la primera actividad económica en el mundo, además de ser considerado un sector clave en países emergentes.

Este crecimiento sostenido tuvo muchas razones: el mejoramiento en la economía de los principales países emisores, el incremento en el número de turistas chinos, así como una mayor apertura por parte del gigante asiático al turismo receptivo, mejores condiciones de seguridad en los países receptores, un importante crecimiento en inversiones en varios sectores del turismo - especialmente el de alojamiento - sumado a una mejora en el transporte aéreo entre otras. Esto sumado a la difusión global de más destinos en redes sociales, logró sostener en las dos últimas décadas records anuales de crecimiento en desplazamiento de personas con fines turísticos. Sin embargo, el turismo es una actividad extremadamente sensible a fenómenos internos y externos: fenómenos climáticos, inestabilidad política y social y en este caso pandemias son agentes de inmediato efecto negativo en este sector.

Si bien esta no ha sido la primera crisis que ha sufrido el turismo en su historia reciente, si ha sido la más estrepitosa. Eventos pasados como la presencia del SARS en Asia y Medio Oriente en 2003 y la burbuja inmobiliaria en 2008 y 2009 incidieron en una reducción del turismo a nivel global, la crisis causada por el COVID-19 no tiene ningún nivel de comparación previa como lo demuestra la figura 1. 
Figura 1: Reducción comparativa de turistas con crisis previas

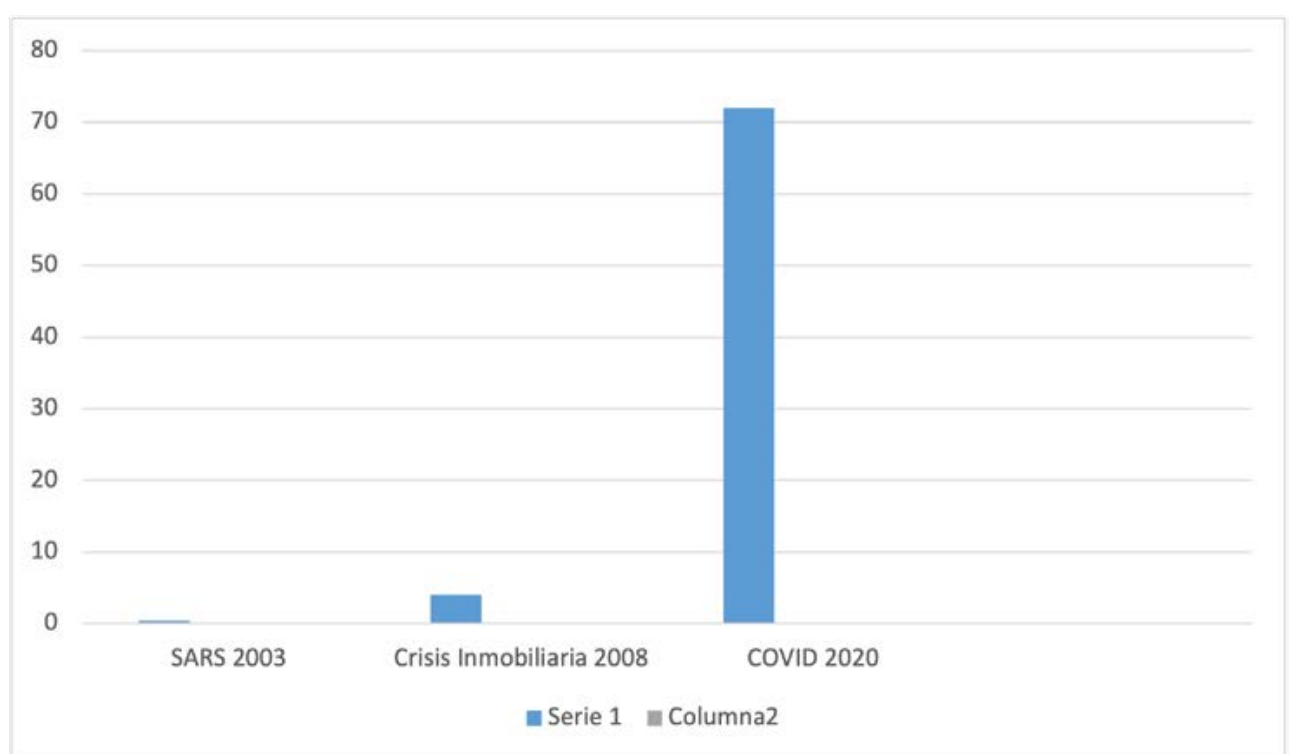

Fuente: OMT (2020b). Elaboración: Autores.

Para octubre de 2019, los noticieros informaban sobre la crisis sanitaria que soportaba la ciudad de Wuhan en China y el confinamiento al que se había sometido a su población, la noticia sonaba tan lejana e imposible de pensar que eso podría suceder en el resto de países. Apenas seis meses después, buena parte de los países occidentales y sus habitantes iniciaban una nueva forma de vida que hasta la fecha implica una serie de restricciones de movilidad y medidas de bioseguridad por doquier. Sin embargo, la acción del virus sobre los países ha sido distinta, siendo los de clima templado los más afectados, así como los de Europa Central y Mediterránea más que los del área Nórdica y con una baja incidencia aún en países africanos (Olcina 2020).

A partir de la diseminación del virus SARS-CoV-2 generado según datos de la Organización Mundial de la Salud (OMS) en China, los diferentes gobiernos a nivel global implementaron acciones de restricción de movilidad y desplazamiento tanto de manera interna en sus países como a nivel internacional: la base innata del turismo: la movilidad para el mes de marzo había desaparecido y se extendería hasta el mes de julio, dejando al sector frente a una de sus peores crisis y la primera del siglo XXI como lo indica la figura 2.

Figura 2: Porcentaje de cierre de fronteras a nivel mundial 


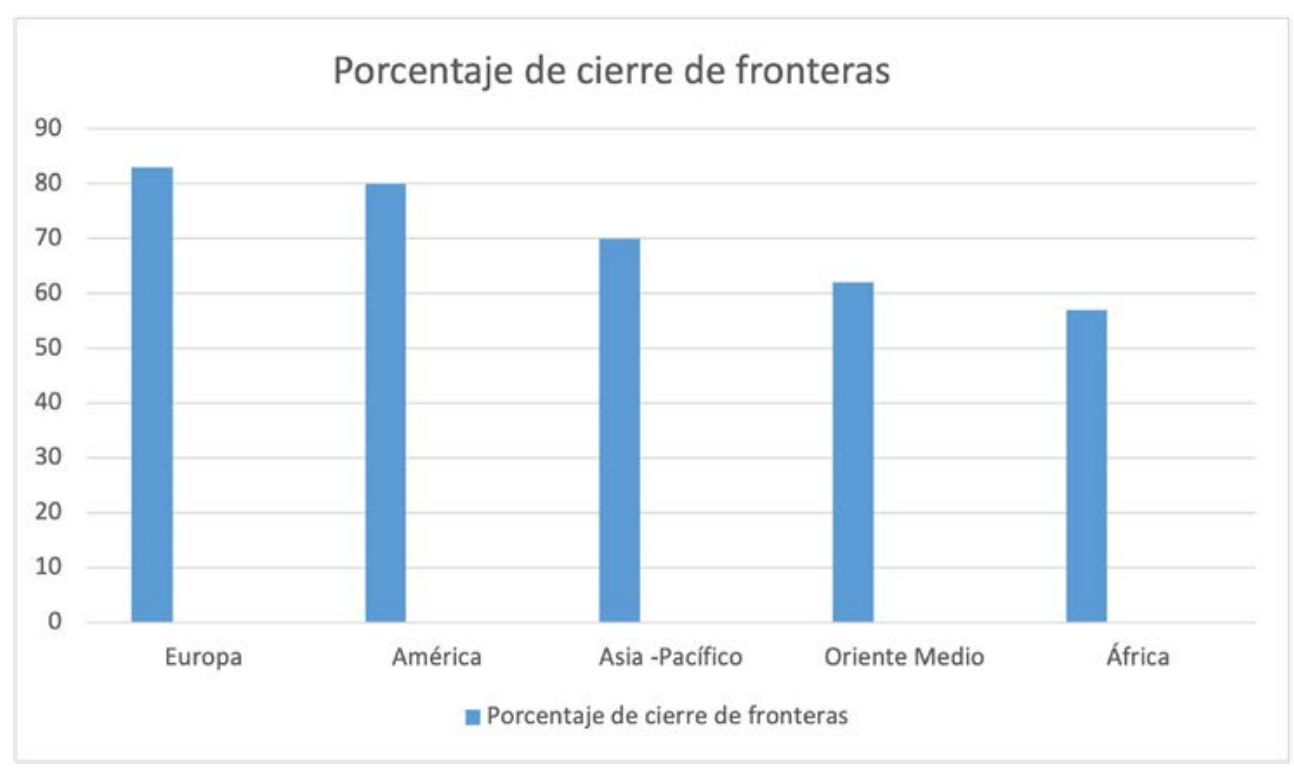

Fuente: OMT (2020a). Elaboración: Autores.

A partir del mes de agosto, algunos países iniciaron una lenta y condicionada apertura de sus fronteras, imponiendo fuertes restricciones y requisitos para el ingreso a sus territorios, siendo la más común la presentación de certificados de seguridad sanitaria como la prueba médica de Reacción en Cadena de Polimerasa (PCR por sus siglas en inglés) con un máximo de vigencia de 72 horas. Esto sumado al miedo de contraer el virus no reactivó los desplazamientos ni a nivel local ni a nivel internacional.

Si bien el confinamiento supuso un impacto a muchos sectores económicos ecuatorianos, el turismo fue el más afectado de todos estos, debido a que el principio de esta actividad es el desplazamiento de turistas y excursionistas, el cual fue restringido de manera nacional e internacional por cuatro meses. Este impacto fue mayor en países o lugares que dependen en buena parte del turismo, donde desde el inicio del confinamiento los sectores directamente vinculados al turismo debieron cerrar sus puertas por alrededor de un año afectando con esto a millones de empleados y rompiendo una de las cadenas de valor más dinámicas e importantes del mundo.

Los datos así lo reflejan, donde según la OMT a partir de marzo de 2020 se evidencia una caída en picado en la llegada de turistas a nivel global y en incremento inédito en el cierre de negocios vinculados a actividades turís- 
ticas. Así lo reflejan las llegadas internacionales que en los primeros diez meses del 2020 cayeron en más del setenta por ciento, como se muestra en la figura 3.

Figura 3: Llegada de turistas internacionales en $\mathbf{2 0 2 0}$

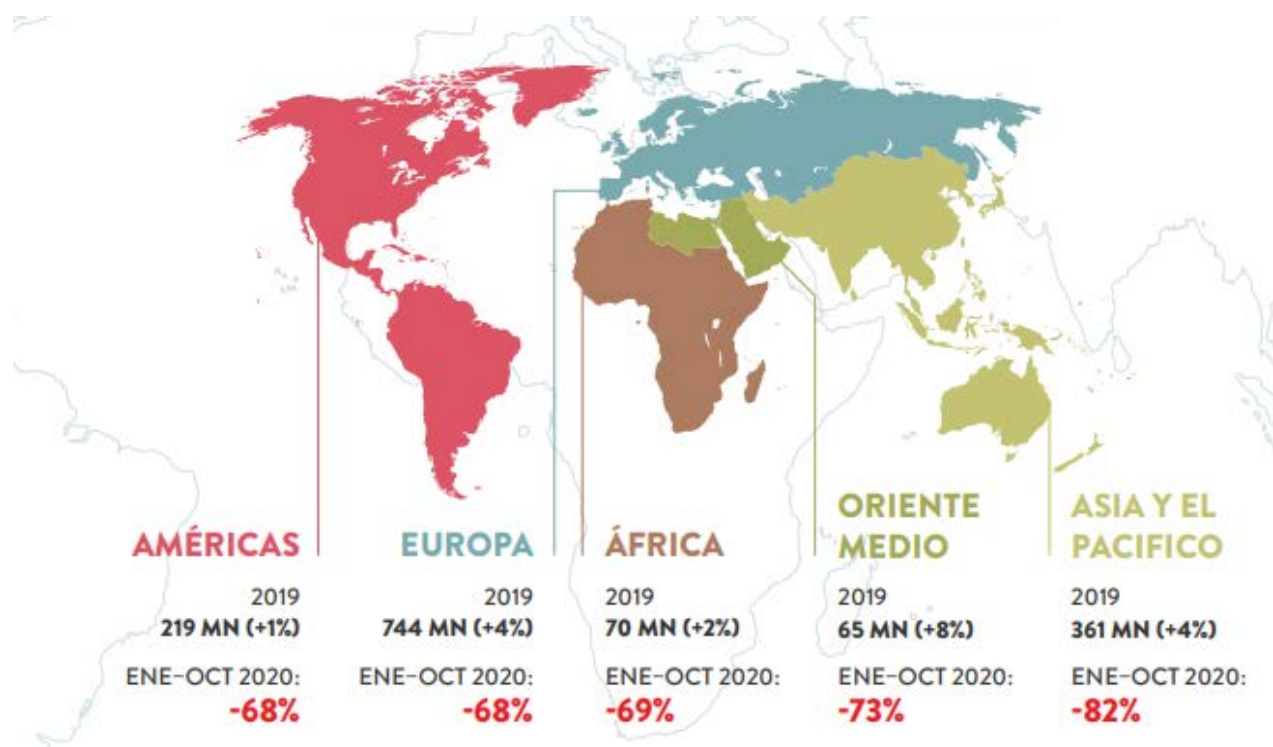

Tomado de OMT, 2020b, p. 5.

Quizás el problema más serio que enfrenta el turismo después del cierre de fronteras en 2020 es la incertidumbre, ya que el confinamiento en buena parte de los países europeos ha sido impuesto debido a una segunda ola y quizás ya a una tercera. Si bien para cuando se escriben estas líneas la distribución de las vacunas lleva aproximadamente dos meses, muchos países europeos han vuelto al confinamiento por algunas semanas. Las proyecciones de reapertura de sitios turísticos han sufrido un vaivén que no le ha permitido al sector tener una idea clara de proyecciones de recuperación ni siquiera para 2021.

Y las consecuencias en el ámbito económico han sido las peores de la historia del turismo en los últimos cien años: según la OMT, se estima que hasta octubre de 2020 el sector perdió un aproximado de 935 mil millones de dólares a nivel global, una cifra que ha hecho retroceder al sector treinta años, ya que las cifras son similares en número de llegadas de turistas internacionales e ingresos a las de 1990. Las previsiones de la OMT tampoco pueden ser claras, ya que aún existen países en confinamiento en el continente 
europeo a pesar de la vacunación masiva que están llevando a cabo los países desarrollados; no se conocen los efectos finales de la pandemia en el ámbito de los establecimientos turísticos que podrán sobrevivir y durante este 2021; y menos aún se conoce cuáles serán los efectos en los turistas, el principal componente de esta actividad, la cual deberá poner a prueba su capacidad de resiliencia como nunca antes.

\section{I.2. Composición turística Urbano Rural en el Ecuador}

El Ecuador tuvo registrados 22393 prestaciones de servicios turísticos para el año 2020, concentrados en 655 parroquias urbanas y rurales a nivel nacional, que equivale al 44\% de representación nacional (figura 4). El 96\% de prestadores de servicios se encuentran en la parte urbana, considerando a las cabeceras cantonales y apenas el $4 \%$ en el entorno rural.

Figura 4. Prestadores de servicio registrados en parroquias urbano rurales del Ecuador 2020

ECUADOR - ESCALA 1:5.000.000

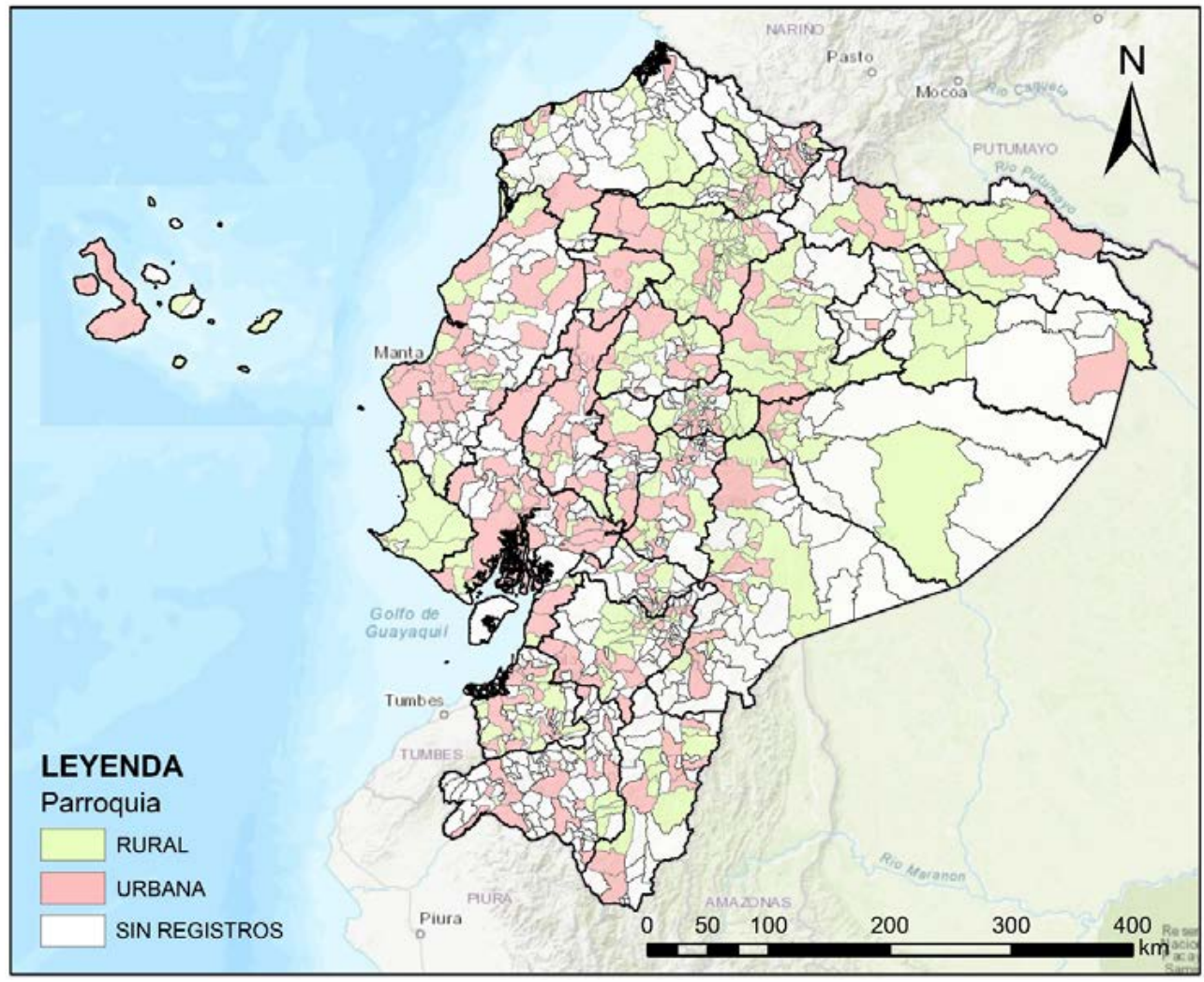

Elaborado por: Villagrán P. 
Si se analiza la presencia de los prestadores de servicios en el territorio ecuatoriano, es evidente observar en la figura 5 que, 9 de cada 10 empresas turísticas se encuentran ubicados en la parte urbana. Se destacan las ciudades de Guayaquil y Quito como las urbes de mayor número de empresas registradas. En un segundo grupo se encuentran las ciudades de Cuenca, Manta, Machala, Ambato, Baños y Riobamba. En el caso de los emprendimientos en el espacio rural es muy limitada; a pesar de que allí se encuentran áreas protegidas, comunidades vivas y una vasta diversidad de recursos naturales.

Figura 5. Concentración de prestadores de servicio urbano rural en el Ecuador

\section{PRESTADORES DE SERVICIO REGISTRADOS EN PARROQUIAS URBANO RURALES DEL ECUADOR \\ 2020}

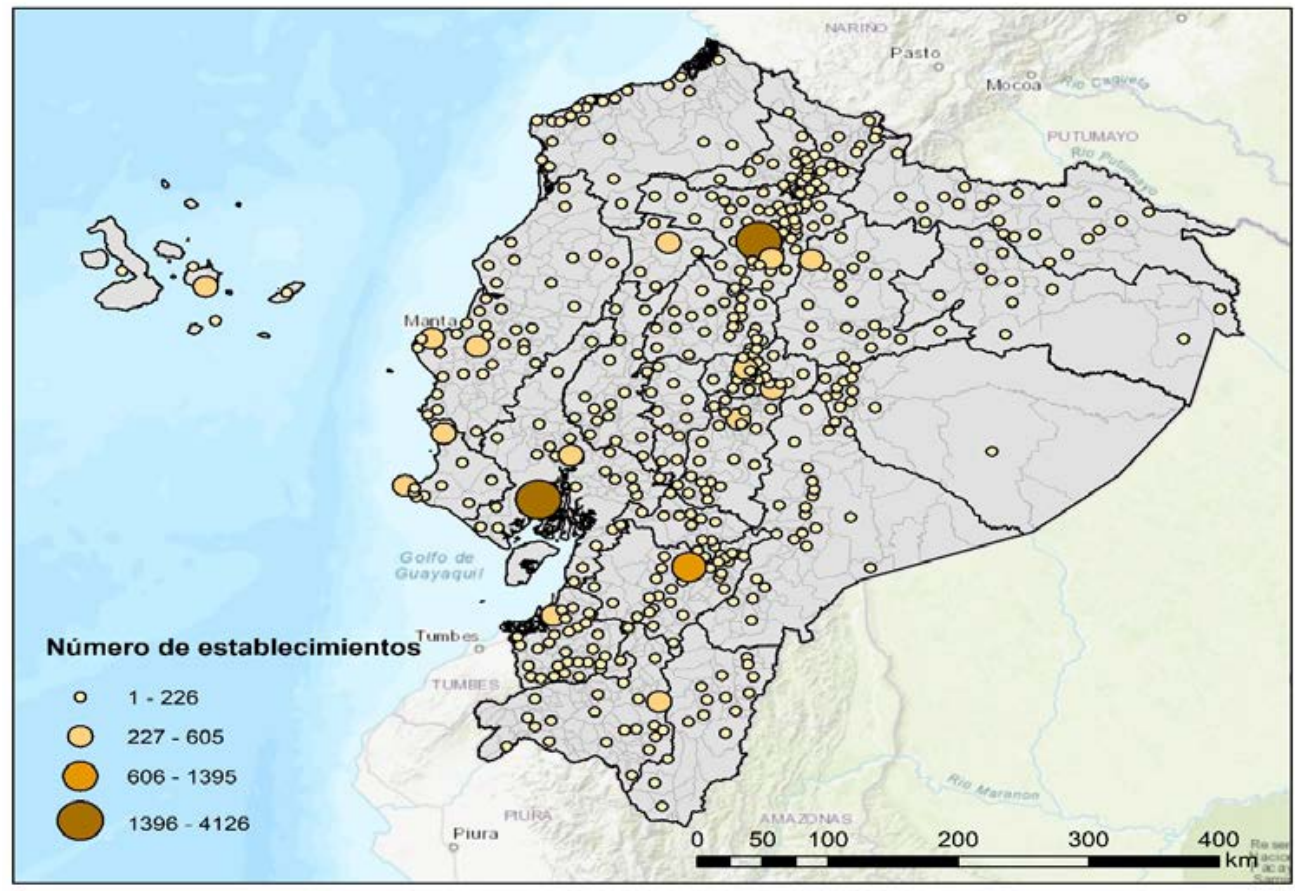

Elaborado por: Villagrán $P$.

En la figura 6 se observa que la única actividad turística con mayor predomino en el ámbito rural es el registro de los Centros de Turismo Comunitario (CTC) destacándose las comunidades orientales organizadas, siendo así que 5 de cada 10 CTC, están en la región amazónica; sin embargo, es contun- 
dente la presencia en la zona urbana de 6 de cada 7 actividades turísticas (alimentos y bebidas, alojamiento, intermediación, operación e intermediación, parques de atracción estables y transporte turístico).

Figura 6. Actividades turísticas concentradas en parroquias urbanas y rurales

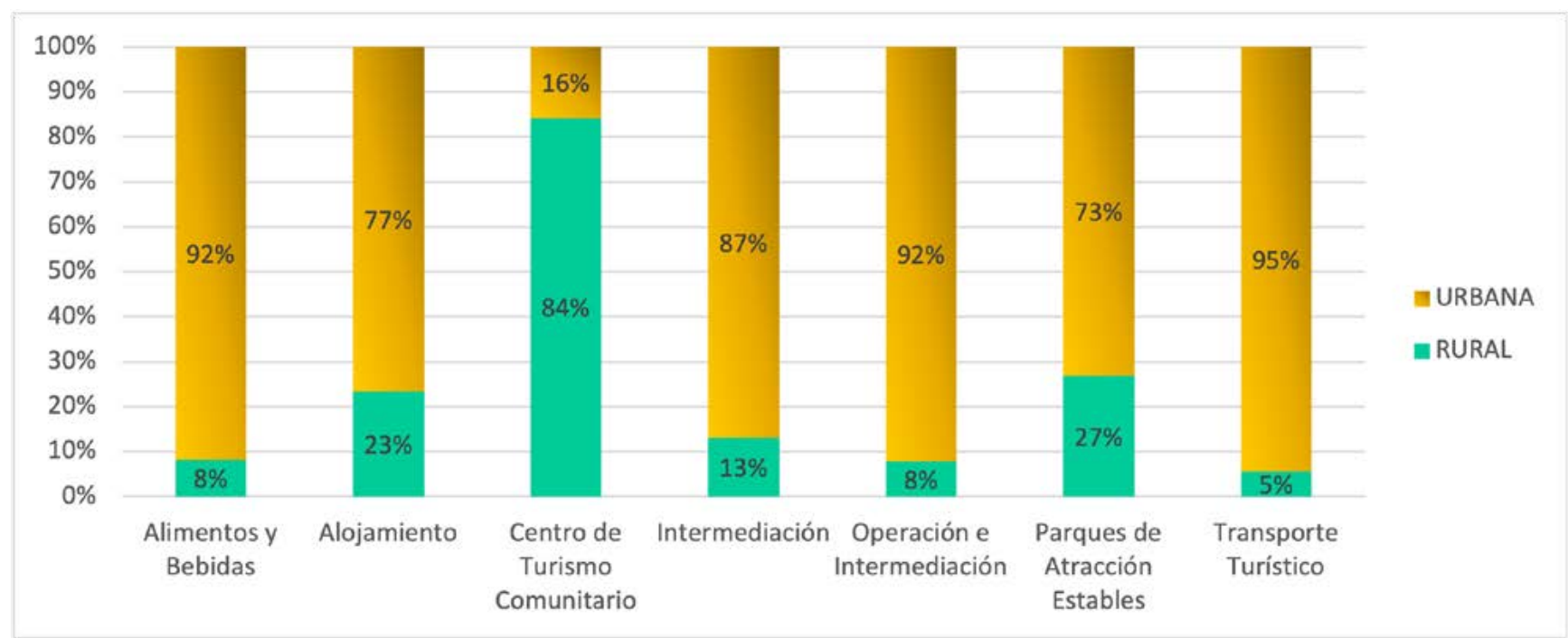

Tomado de: Garrido et al, 2021. Consolidado Nacional 2020. P.76

La generación de empleos en el turismo es muy significativa para el país, antes de la crisis Covid-19 el Ecuador, según el consolidado nacional registró a 120569 empleos (Ministerio de Turismo del Ecuador [Mintur] 2020). En la figura 7 se observa que las principales provincias con importante concentración de empleos son Pichincha y Guayas, luego aparecen las provincias con vocación turística como son Manabí y Azuay; mientras que, las provincias con menor concentración de empleo turístico son Carchi, Bolívar y Zamora Chinchipe. 
Figura 7. Concentración de empleados en las actividades turísticas del Ecuador Nacional

CONCENTRACIÓN DE EMPLEADOS EN LA ACTIVIDADES TURÍSTICAS DEL ECUADOR

ECUADOR - ESCALA 1:5.000.000

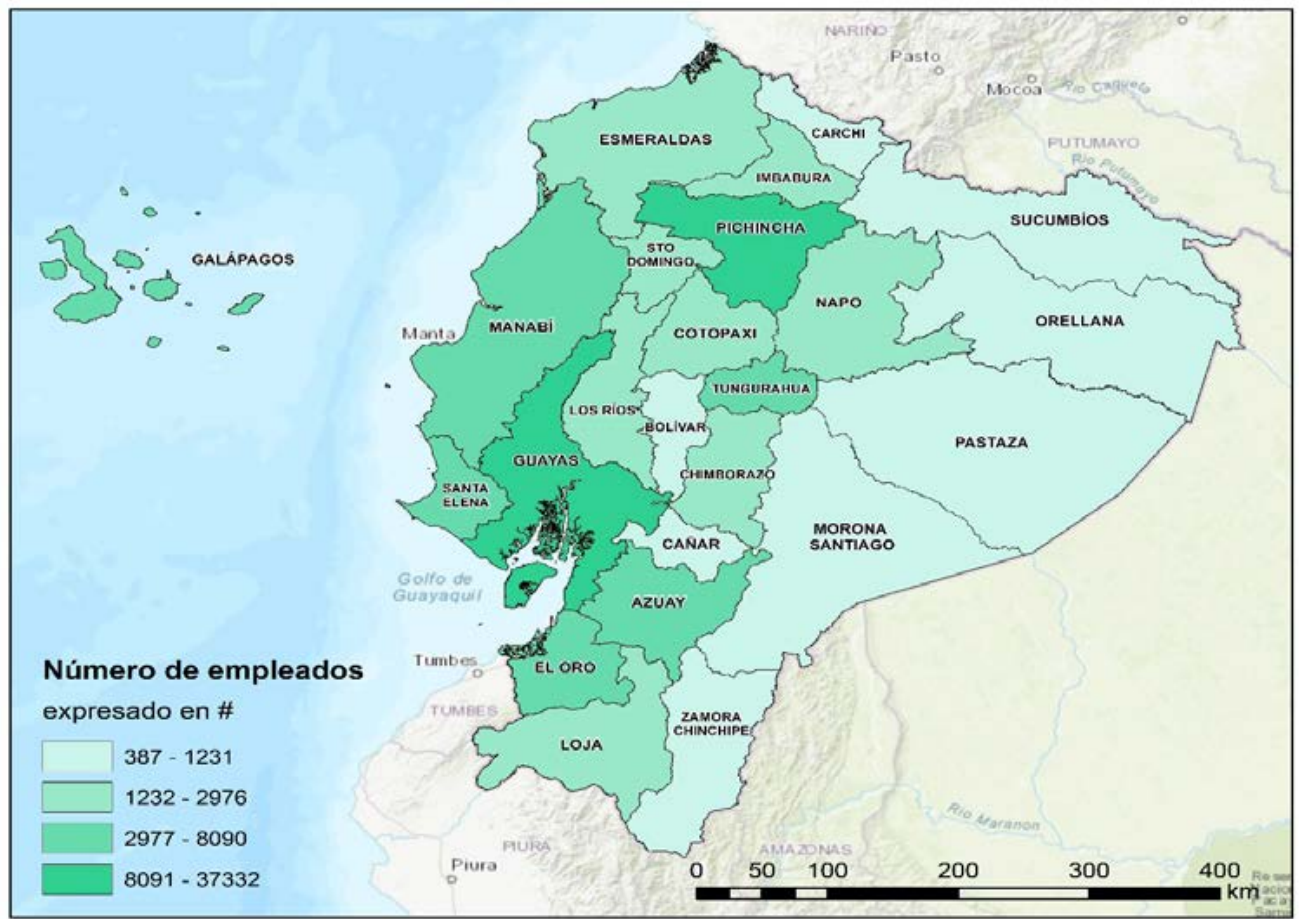

Elaborado por: Villagrán $P$.

En la figura 8 se evidencia la relación entre los empleos turísticos y las zonas de planificación nacional. 6 de cada 10 empleos se identifican en la zona 9 (Quito) y zona 8 (Guayaquil), lo cual indica el centralismo existente en el país, tomando en cuenta que los aeropuertos internacionales de alto tráfico aéreo se localizan en las dos zonas de planificación. 
Figura 8. Relación empleos vs zona de planificación nacional

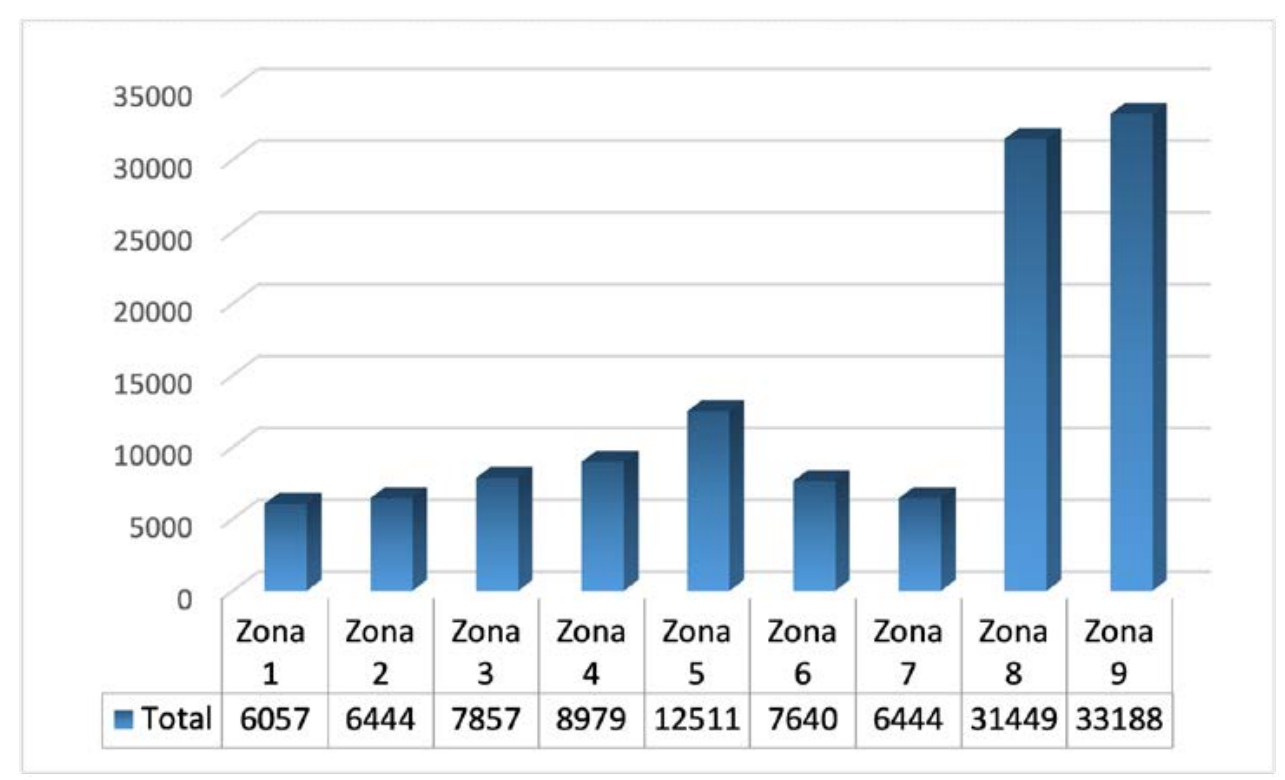

Tomado de: Garrido et al 2021. p. 88.

\section{I.3. Principales elementos del plan de reactivación turístico nacional}

A partir de esta crisis el Ministerio de Turismo del Ecuador estableció un Plan de Reactivación Turística, cuyo principal objetivo es:

Generar una reapertura ordenada y segura de actividades en el sector turístico en todo el territorio nacional, estableciendo medidas, protocolos de prevención que ayuden a un óptimo funcionamiento de la cadena de valor del sector turístico evitando riesgos de contagio del virus COVID 19 a trabajadores, empleados, clientes y ciudadanía en general, con una gestión de control eficiente que aseguren la práctica de tales medidas y protocolos como un estándar nacional. (MINTUR, 2020c. p. 7)

Para ello se fundamentó en tres temas claves: evitar un impacto de gran escala en el empleo, liquidez y soporte al tejido empresarial y estudio con la demanda para conocer su nuevo comportamiento. Para lograr esto se definieron varios lineamientos, los cuales se han dado en diversa magnitud, escala e intensidad, que son: 
1. Una campaña masiva para la demanda y el nuevo comportamiento esperado.

2. Desarrollo de estrategias interinstitucionales que permitan sostener y plasmar el objetivo planteado.

3. Implementar un sistema de control en las empresas catastradas a nivel nacional para que cumplan los protocolos de bioseguridad.

4. Incremento en uso de plataformas digitales para llegar a la demanda y a la oferta con mensajes de importancia sectorial.

5. Finalmente, lograr posicionar la importancia de sellos de certificación como el Safe Travel del World Tourism Council, como un estándar de operación durante y en la post pandemia.

Cada actividad registrada en el ministerio tuvo un plan de reapertura individualizado, con una semaforización acorde a lo que se adoptó a nivel país. Aunque la mayoría de cantones llegó a finales del 2020 como amarillo, en el primer trimestre del 2020 algunos han regresado a rojo y esto ha incidido en un retroceso de las liberalizaciones de operación que venía adoptando el sector.

A inicios de la pandemia y por cuatro meses se trabajó en 5 mesas de trabajo habilitadas para reactivación del sector. En ellas se invitaron a representantes de las 5 actividades turísticas participando de manera activa (alojamiento, alimentos y bebidas, tour operadores, agencias de viajes, transporte turístico), personas en la academia, 15 universidades y 3 institutos, 126 participantes del sector turístico, quienes se juntaron en 34 reuniones alrededor de y temas trascendentales:

1. Mesa de cuantificación del impacto que tuvo como meta el tratar de configurar el alcance de la crisis.

2. Mesa laboral, tributaria, financiera, donde se discutieron temas laborales y los requisitos de liquidez de las empresas en pos de mantener lo máximo posible del empleo.

3. Mesa de competitividad donde se discutieron medidas que podrían implementarse para recuperar la golpeada imagen del país. 
4. Mesa de promoción y cooperación donde se definieron lineamientos para resetear la demanda y proyectar un inicio con el mercado doméstico.

5. Mesa territorial donde se priorizó el trabajo con las provincias y municipios, tratando de satisfacer las necesidades y expectativas que tienen hasta el momento estos lugares.

Como un producto de este trabajo, se sintetiza a continuación los principales lineamientos y demandas que se plantearon con base en este trabajo colaborativo:

1. Demandar la priorización del sector turístico dentro del plan de reactivación del Estado ecuatoriano.

2. Cuantificación del impacto y estimación de pérdidas de la industria como base para obtener beneficios y programas económicos que sostengan la empresa y el empleo.

3. Facilidad para la suspensión de jornada laboral y pago de remuneración a los trabajadores conforme posibilidades de la empresa, con base en acuerdo entre las partes.

4. Eliminación o diferimiento en pago de tributos causados en el 2020 y 2021 al Estado central y gobiernos locales.

5. Necesidad urgente de financiamiento para que los prestadores de servicios turísticos puedan tener liquidez para sobrevivir a la emergencia sanitaria.

6. Desarrollar una regulación para el pago de reembolsos o devoluciones a los usuarios que se vean afectados por esta pandemia y no puedan recibir los servicios adquiridos.

7. Desarrollo e implementación de estrategias para combatir la informalidad.

8. Generar protocolos preventivos para los diferentes prestadores de servicios turísticos ante eventos suscitados por la emergencia sanitaria presentada en el país.

9. Revisión y adaptación de la Normativa vigente, para que se adecue y esté alineada al nuevo escenario de funcionamiento. 
10. Generación de una campaña promocional interna y externa para no perder posicionamiento y dar a conocer que el país está tomando medidas de protección a los visitantes.

11. Establecer incentivos específicos para el turista ecuatoriano y extranjero a fin de motivar el desplazamiento y generación de divisas.

12. Establecer acciones para la capacitación en protocolos de bioseguridad a los establecimientos en los diferentes territorios del país.

13. Mejora y adecuación de los espacios de visita en los diversos territorios.

Lastimosamente las mesas no lograron tener continuidad y el agravamiento de la crisis repercutió en una ruptura del trabajo conjunto de los actores sectoriales. Por otro lado, el Estado no se mostró capaz de lograr los lineamientos o acuerdos establecidos en el tiempo y forma solicitada por los actores sectoriales, a lo cual se sumó la finalización del gobierno nacional a mayo del 2021, por lo que los puentes de trabajo conjunto se han dilatado para quien asuma la presidencia y conducción del estado a partir de junio de este año.

Pese a esto, lo más rescatable fue el anhelo conjunto de reactivarse luego de la crisis y a palabras del Viceministro de Turismo, Msc. Ricardo Zambrano, desarrollar un "trabajo colaborativo y articulado entre el sector público, privado, académico que es fundamental para la reapertura y reactivación del turismo en el Ecuador (Mintur 2020, p. 31).

\section{Metodología}

El tipo de investigación fue descriptiva, se caracterizó varios aspectos del impacto del COVID-19 en el sector turístico urbano del país. Se utilizó una metodología mixta, cualitativa en cuanto se establecen características descripticas del impacto en el turismo urbano. Mientras que en lo cuantitativo se exponen varias encuestas realizadas por los investigadores durante el 2020.

Los autores han participado en varios grupos de investigación desde marzo del 2020, por lo que este capítulo recoge varios de los resultados obtenidos, en torno al turismo urbano: 
- El primero fue una encuesta nacional a empresas turísticas, realizadas a 391 PYMES de 23 de las 24 provincias del Ecuador, que pudo realizarse en conjunto con la Federación Nacional de Cámaras de Turismo y la Cámara de Turismo de Pichincha. El grado de confiabilidad fue del $95 \%$, con un margen de error de $+/-5$ y una varianza del $50 \%$. Las encuestas se aplicaron contactando directamente a los responsables de las empresas turísticas del país, a través de una plataforma virtual con contacto directo a los encuestados. Dicha medición se realizó entre mayo y julio del 2020.

- Una siguiente encuesta fue realizada junto con la Red de Profesionales de Turismo (REDPROTUR) núcleo Pichincha, en donde se caracterizó el impacto en el empleo. Dicho estudio, alcanzó un número de 129 respuestas, que representan a un grado de confiabilidad del $95 \%$, un margen de error de $+/-8$ y una varianza del $50 \%$. Si bien se observó, que hubo una concentración de encuestas en la ciudad de Quito, se destaca que el sondeo pudo recoger información de al menos 15 provincias, de las 24 del país. Además, se recabaron datos de profesionales de las principales ciudades y de otras que son los principales destinos turísticos del país.

- De igual forma, una tercera encuesta que se realizó con el Ministerio de Turismo y un grupo de 14 universidades, que para finales del 2020 caracterizó la demanda post COVID, en un nuevo escenario de consumo que tiene mucha afectación al tema urbano. "El total de encuestas receptadas en el periodo de levantamiento de información fue de 10039, de las cuales a nivel nacional fueron recolectadas 1595 observaciones y las receptadas por las universidades participantes fueron 8444. Dentro del estudio se encontraron 1152 registros duplicados, los cuales previo análisis fueron suprimidos, dejando un total de 8887 observaciones. A su vez, dado que la población objetivo dentro de esta encuesta está definida por las personas que acceden a dar su consentimiento a responder las preguntas de la encuesta y las personas que tienen una edad mayor a 16 años, con estas consideraciones se procedió a identificar los registros que cumplen con las dos premisas requeridas, filtrando además los datos perdidos, dejando un total de 8329 ob- 
servaciones para el análisis final de los resultados" (MINTUR 2020b, p.8). Estas encuestas se hicieron a nivel nacional, con ayuda de las instituciones académicas y representan un grado de confiabilidad del $99 \%$, un margen de error de $+/-1,5$ y una varianza del $50 \%$.

- Finalmente, se obtuvo varia información de un capítulo de libro que se trabajó para un documento de la FLACSO. A ello hay que agregar, un trabajo en edición sobre el Impacto del COVID en el turismo, a nivel nacional, de los autores, que al momento está también en edición en la Universidad Internacional del Ecuador. Dichos documentos están en proceso de edición, pero son complicaciones e interpretaciones de diversas variables estudiadas del impacto del COVID 19 en el Ecuador.

\section{Análisis y resultados}

\section{I. Impacto en la estructura empresarial}

Tal como ya se ha manifestado, 9 de cada 10 empresas del Ecuador están en parroquias urbanas, por lo que los temas que se exponen a continuación, pese a que son una nuestra a nivel nacional, mayormente caracterizan lo acontecido en este espacio. El primer hallazgo significativo fue que 8 de cada 10 empresas estuvieron en el 2020, ya sea cerradas o en pausa operativa a la espera de nuevos acontecimientos (autores). Para mediados de año se estimó que aproximadamente un $13 \%$ del catastro nacional eran empresas que habían optado por desaparecer, si se contrasta estos números con los catastros nacionales a febrero del 2020 y 2021, se observa lo siguiente:

Tabla $\mathbf{N}^{0} 1$. Comparativo de decrecimiento por sector

\begin{tabular}{llll}
\hline AÑO & $\mathbf{2 0 2 0}$ & $\mathbf{2 0 2} \mathbf{I}$ & Var. \\
\hline Alimentos y Bebidas & 14747 & 11659 & $-20,94$ \\
\hline Alojamiento & 4205 & 4326 & 2,88 \\
\hline Centros de Turismo Comunitario & 38 & 39 & 2,63 \\
\hline Intermediación & 374 & 353 & $-5,61$ \\
\hline Operación e Intermediación Turística & 2308 & 2323 & 0,65 \\
\hline Parques de Atracciones Estables & 239 & 233 & $-2,51$ \\
\hline Transporte Turístico & 582 & 557 & $-4,30$ \\
\hline TOTAL GENERAL & $\mathbf{2 2 4 9 3}$ & $\mathbf{1 9 4 9 0}$ & $-\mathbf{- 1 3 , 3 5}$ \\
\hline
\end{tabular}

Adaptado de Ministerio de Turismo 2020a. 
Para finales de año se observó cierta recuperación, especialmente en ventanas de tiempo donde se flexibilizó la movilidad interna. Aunque también hay que mencionar que estas ventanas de tiempo tuvieron que afrontar medidas sorpresivas, como el cierre y confinamiento impuesto a 2 días de las vacaciones de fin de año.

Del estudio que se realizó para mediados del 2020, se obtuvo un valor de pérdida promedio mensual de 336 millones de dólares. Extrapolando este dato con el reporte publicado por el Ministerio de Turismo, donde se observa una caída en ventas en el año 2020, respeto al 2019, de 2.811 millones de dólares (Ministerio de Turismo 2021), se obtiene que hubo una pérdida promedio entre marzo y diciembre del 2020 de 312 millones por mes, dato relativamente similar al expresado por las empresas que fueron encuestadas.

Esta caída no solo impactó fuertemente en el tejido urbano, sino que tuvo alcances regionales y nacionales, puesto que agricultores, pescadores, artesanos y otros proveedores directo de la cadena de valor del turismo, manifestaron que sus ingresos habrían reducido drásticamente.

El capital humano del sector fue sin duda uno de los más afectados. Tal como se detallará a profundidad en este mismo artículo han sido gran cantidad de personas las que sufrieron reducción de carga laboral y sueldo, que fueron cesadas temporalmente o que fueron separadas definitivamente, hechos ocurridos a la luz a una reforma al Código de Trabajo que flexibilizó estos escenarios. En un estudio publicado por la organización Internacional del Trabajo y el ministerio de turismo para finales del 2019, se estimó que el empleo directo e indirecto del turismo rondaba de entre los 540 mil a 810 mil empleos. De este monto, en el estudio realizado a mediados del 2020, se observó separación definitiva a cerca de 170 mil empleados, cifra que seguramente habrá incrementado en los últimos meses. No existe un dato oficial sobre la caída del empleo, pero se puede estimar por lo visto que 1 de cada 3 empleos se perdieron en el 2020, más aún al no existir un programa de apoyo laboral por parte del Estado; la empresa privada mayormente ha desvinculado a su personal, aunque no se hayan reportado oficialmente estas separaciones.

Las empresas encuestadas manifestaron que su necesidad principal ha sido crédito para sostener una nómina básica y pagos de impuestos y otros haberes de servicios básicos. A grandes rasgos el préstamo promedio es de alrededor 
de 60 mil dólares, con una tasa nominal de un 5\% (frente al 9\% promedio que se encuentra en el país a marzo del 2021). Demandan un plazo de al menos 5 años y un colchón de 12 meses de gracia. Sin embargo, aunque el gobierno creó el programa Reactívate Ecuador, que se expuso en la introducción de esta investigación, no se ha logrado que la banca pública o la privada confíe en el sector y desarrolle un producto financiero de estas medidas. Pese a que las tasas de apalancamiento son buenas y que los activos son una garantía de peso, no hay sintonía con el sector y en el primer trimestre del 2021 solo se observó un desencanto total, puesto que la mayoría de solicitudes crediticias fueron negadas, aduciendo que no cumplen con flujos necesarios y suficientes, sin tomar en cuenta que casi todo el 2020 las operaciones no superaron más del $30 \%$ en sus mejores momentos.

Un tema que complicó más la situación empresarial fue que el 2021 es un año electoral en el país, a lo que se suma una caja fiscal ajustada por varios asuntos de emergencia que ha tenido que irse superando por la pandemia. Los dos finalistas a la presidencia, Lasso y Arauz, coinciden en algunos factores para el sector turístico:

- Moratoria de pagos de obligaciones tributarias.

- Implementación de Impuesto al Valor Agregado de cero por al menos 2 años.

- Facilitar el acceso a crédito para la reactivación de las empresas.

- Alentar el consumo interno.

Sin embargo, estas son sólo ideas que de plasmarse podrían ayudar, pero que dentro de la dificultad de tener una vacunación rápida y efectiva en el país son paliativos que son esperados por los empresarios del sector. Lo que sí es muy real es la precariedad en la que han quedado varias empresas y su difícil recuperación en el corto plazo. 


\subsection{Impacto en el talento humano}

Ecuador es uno de los países latinoamericanos donde la formación del talento humano vinculado a los distintos ámbitos de la hospitalidad forma parte de alrededor del setenta por ciento de las universidades y del sesenta por ciento en los institutos técnicos, por lo que la formación y capacitación del recurso humano vinculado al turismo es importante. Buena parte de estos profesionales del turismo se emplean en el sector privado, el cual justamente requiere una amplia diversidad para poder mantener sus servicios.

Así, con la llegada del confinamiento los efectos para ese recurso humano dentro del ámbito turístico fueron devastadores, un sector que ha retrocedido cerca de treinta años en apenas doce meses y que ha dejado una crisis económica sin precedentes en el turismo mundial. Y quizás a más a de las pérdidas económicas de los inversionistas privados que son el verdadero motor del turismo, ha sido el empleo formal ${ }^{1}$ el más golpeado con esta crisis.

Si bien el turismo en el Ecuador para 2019 aportaba con el 2\% del PIB, su impacto sobre el empleo directo e indirecto era importante. Así:

En el Ecuador, el estudio del mercado laboral del sector turístico de Ecuador marca dos escenarios, que van desde las 522508 a las 810246 personas con empleo adecuado y subempleo (Organización Internacional del Trabajo [OIT], 2019). El empleo adecuado va entre 181794 a 305807 personas en los dos escenarios, lo cual representa el 10,2\% del empleo adecuado a nivel país, luego de los subsectores agrícolas $(29,7 \%)$ y comercio (18,5\%). A nivel general, el sector reportó un promedio de 11,5 empleos por empresa, a febrero del 2020. En un estudio de rangos de empleo, se observa una mayor concentración (91,72\%) de empresas turísticas que tienen un rango de hasta 25 empleos. (Garrido et al. p.80)

Si bien desde el inicio del confinamiento en Ecuador el 16 de marzo de 2020 el sector turístico tuvo un fuerte impacto, los dos primeros sectores que no pudieron seguir operando de manera inmediata y de ninguna forma fueron: operación turística y transporte turístico. A los pocos días el sector de aloja-

1. En Ecuador, se considera a un empleo formal cuando existe un contrato de trabajo entre el empleado y el empleador donde este último recibe todas las compensaciones $\mathrm{y}$ beneficios de ley. 
miento comenzaba a perder sus pocos huéspedes que de a poco iban dejando estos lugares para recluirse por los siguientes meses en sus casas. Así también después de algunas semanas las aerolíneas terminaban sus vuelos humanitarios y detenían la actividad aeronáutica. Si bien una gran cantidad de restaurantes tuvo que cerrar sus puertas, aquellos que contaban con el servicio de entrega a domicilio lograron mantenerse operativos durante los meses de confinamiento.

Junto con los operadores y el transporte turístico, los guías de turismo quizás llevaron la peor parte, ya que, al no mantener un empleo formal con las agencias de viajes, no gozaban de los beneficios como seguridad social, la cual en este caso activó un modelo de seguro de desempleo que benefició a miles de ecuatorianos. Miles de guías nacionales, especializados, locales y comunitarios vieron reducir sus ingresos a cero con el cierre de los aeropuertos y el inicio del confinamiento. Con ellos, operadores y empresarios de transporte turístico (terrestre, aéreo, marítimo y fluvial) debieron despedir a buena parte de su personal en los primeros tres meses de inactividad. Para el mes de septiembre, la crisis ya no solo implicaba el despido de empleados, sino el cierre definitivo de muchas agencias de viajes operadoras, mayoristas y empresas de transporte turístico.

El sector de alojamiento también presentó serios problemas. A las pocas semanas del confinamiento, al igual que el sector de operación turística despidieron a buena parte de su personal; sin embargo, a los pocos meses ya se registraban los primeros cierres de hoteles medianos y pequeños junto con hostales y pensiones. Para finales de 2020, ya las grandes cadenas también eran víctimas de la crisis, hoteles como el Marriot Quito cerraron sus puertas. Sin embargo, en algunas ciudades algunos sitios de alojamiento sirvieron como lugares autorizados para realizar las cuarentenas obligatorias establecidas por el Gobierno, lo cual logró mantenerlos activos hasta la reapertura parcial de las actividades en el mes de julio.

Así, a los tres meses del inicio del confinamiento un estudio de la Red de Profesionales del Turismo (REDPROTUR) realizado justamente a los profesionales en este sector dentro de 24 ciudades del Ecuador, determinó que " 9 de cada diez profesionales manifestaron que la crisis le llegó manteniendo una relación laboral, ya sea como libre ejercicio (4 de 10), empleo privado (3 de 
10) o en el sector público o academia (1 de cada diez)" (REDPROTUR 2020, p. 4). Sin embargo, apenas se inició el confinamiento, las empresas tomaron acciones de acuerdo a algunas variables, entre las que podemos anotar las siguientes:

- Tiempo de trabajo del empleado en la empresa.

- Rendimiento previo.

- Facilidad del empleado para funcionar de manera polifuncional.

- Cálculo de valores a cancelar en caso de despido intempestivo.

De acuerdo a estos parámetros las primeras acciones de las empresas fueron suspender temporalmente la actividad laboral de los empleados, aplicar el teletrabajo, reducir la jornada laboral junto con una reducción del salario o en último caso despedir a sus empleados. En este contexto, dentro del mismo estudio los datos de REDPROTUR arrojaban el siguiente escenario:

\section{Figura 9. Acciones tomadas por las empresas en relación a la empleabilidad urbana}

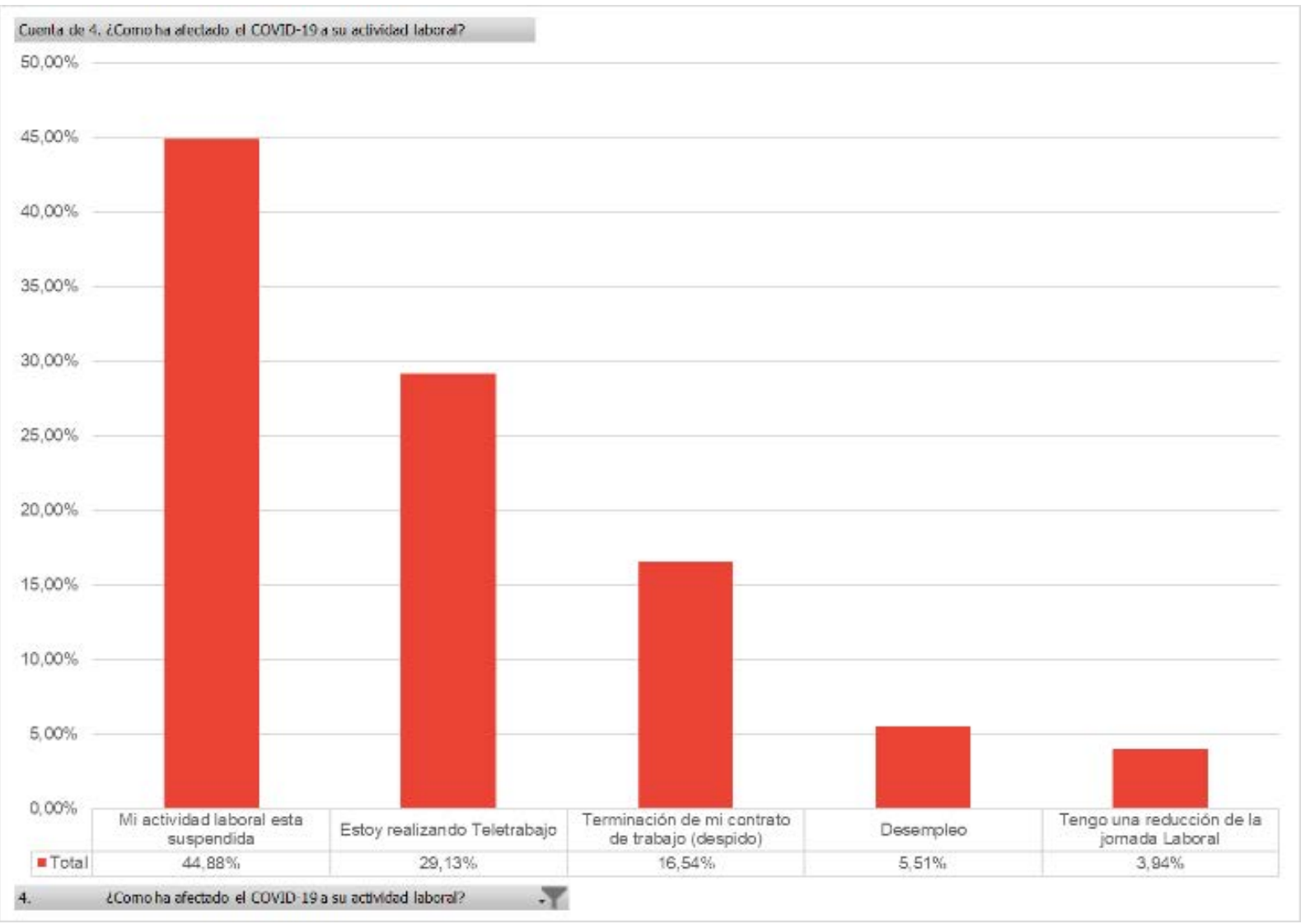

Fuente: Tomado de REDPROTUR, 2020, p. 4. 
Debido a que buena del recurso humano que laboraba en el sector turístico había tenido una formación previa, esto les daba la posibilidad de medir los tiempos de recuperación de la actividad, en lo cual según la misma encuesta más del $60 \%$ aseguraban que el turismo tardaría más de seis meses en iniciar una recuperación, previsión que al final terminó siendo válida para el caso ecuatoriano.

Para mediados del 2020, la Asamblea Nacional, analizando todos los escenarios que las empresas venían adoptando de acuerdo a su actividad, aprobó la denominada "Ley Orgánica de Apoyo Humanitario", la cual legalizaba de cierta manera la reducción de la jornada laboral junto con una reducción salarial a los empleados privados y además que en caso de cierre definitivo de las empresas, los trabajadores perdían el derecho a las indemnizaciones de ley. Con esta nueva normativa gran parte de las empresas turísticas se acogieron a estas medidas con el fin de mantenerse a flote, dando como resultado los siguientes datos:

Figura 10. Adopción de los escenarios establecidos en la Ley

\section{Orgánica de Apoyo Humanitario en las empresas turísticas de carácter} urbano

Estructura Laboral

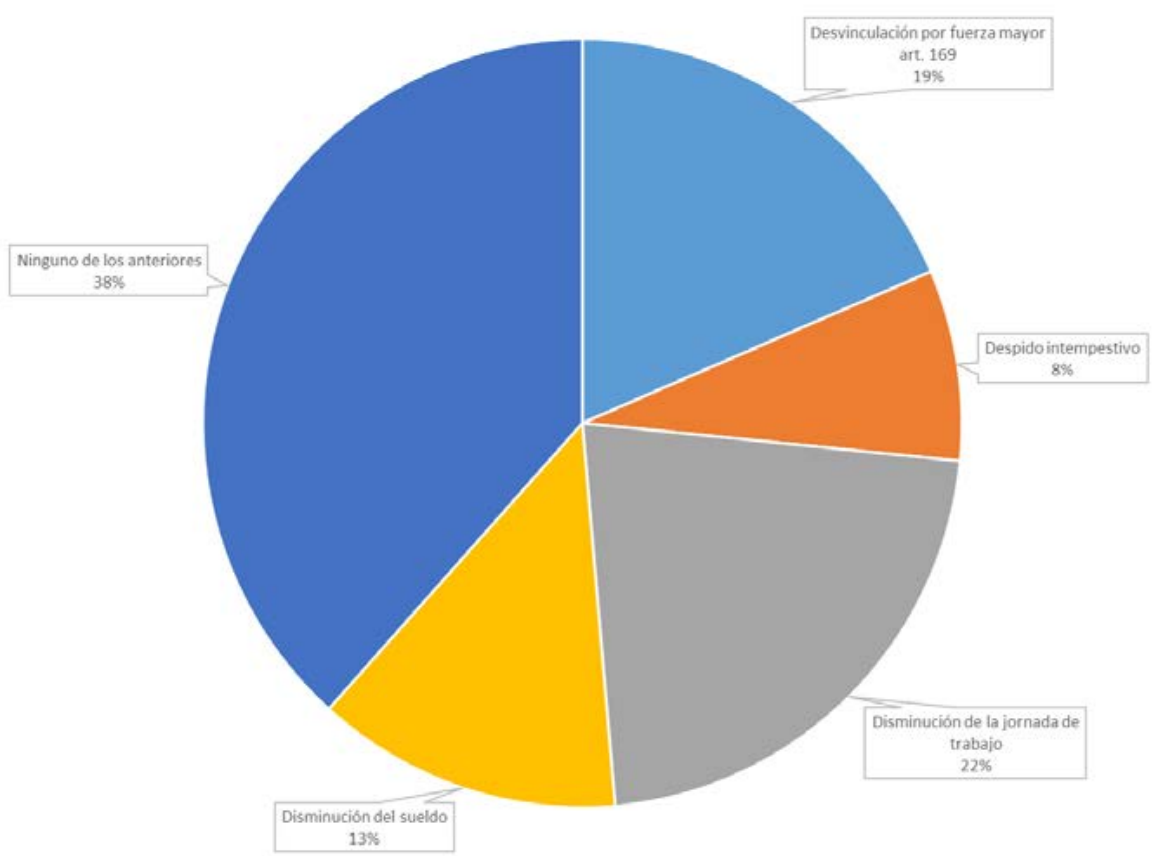

Fuente: Tomado de Garrido et al 2021 p. 82. 
La desvinculación de miles de trabajadores pertenecientes a los diferentes sectores del turismo ha sido evidente, ante lo cual la autoridad competente (Ministerio de Turismo) aún no ha realizado un estudio sobre el real impacto de la pandemia en este sentido. Sin embargo, gracias a estudios realizados como el de REDPROTUR entre otros, se estima una pérdida de cerca del 65\% de los empleos formales del sector, siendo las más afectadas las empresas vinculadas a la operación turística.

\subsection{Análisis de la nueva demanda post Covid-19}

La demanda turística ha condicionado sus desplazamientos por las medidas adoptadas por los gobiernos a toda escala nacional. Se observa hoy una preocupación inminente por la elección a donde viajar. Las ciudades principales del país como Quito y Guayaquil, han contenido los flujos turísticos de ingreso y salida; no obstante, los residentes buscan alternativas para recrearse en espacios configurados para el ocio en zonas adyacentes a la metrópoli. El turismo de proximidad aparece como una oportunidad para buscar evasión y volver al lugar de residencia en periodos de corto tiempo, "los viajes de corta distancia favorecen las empresas y destinos del propio territorio, pero lastran los resultados de agencias de viajes o empresas de transporte" (Canalis 2009). El aspecto geográfico es vinculante en la movilidad humana y aún más en la actualidad de Covid-19, si bien se van generando expectativas de recuperar un pleno disfrute de las actividades turísticas, por el momento las pernoctaciones han disminuido considerablemente. El concepto de turismo de proximidad crea polémicas, "este concepto genera controversia, ya que cuestiona las bases mismas del turismo: la ruptura con la esfera cotidiana y la necesidad de pernoctación" (Díaz-Soria 2014).

En el caso del Ecuador, la nueva demanda presenta características particulares, según el Mintur (2020), “antes y bajo la nueva normalidad, la compañía de preferencia para viajes es la familia íntima, la familia un poco más extendida y los amigos. La seguridad y la menor exposición al virus siguen siendo factores importantes a considerar al momento de viajar". El 71\% de la muestra tomada del estudio determinó que viajará en compañía de familiares y amigos. Es imprescindible mencionar que, cuando se vaya normalizando la movilidad humana, los destinos turísticos preferidos serán los ubicados en la 
región costa; sin embargo, los recorridos que se han realizado en tiempos de pandemia, han sido a zonas rurales cercanas a las principales ciudades. Este último hábito se podrá mantener; debido a la oportunidad que tuvieron los visitantes de consumir servicios turísticos en zonas naturales y el crecimiento de nuevas tendencias mundiales post pandemia.

"El turismo interno es el que más recursos económicos genera dentro del país, que se refleja en una masiva movilización de turistas por todo el Ecuador, permite con esto redistribuir los recursos económicos en todos los sectores turísticos. Son los fines de semana y especialmente los feriados, los utilizados por los ecuatorianos para poder viajar por el país" (Garrido et al. 2021). A más de estas condiciones, los viajeros están cambiando la manera de planificar sus viajes, lo esencial ahora es el aprendizaje de las medidas de bioseguridad, el aumento de las reservas turísticas y las prácticas turísticas de proximidad. Los grandes flujos de viajeros al exterior tardarán todavía un tiempo y para ello los grupos jóvenes tomarán la iniciativa (Smart Travel 2020).

La nueva demanda nacional tiene una predilección por viajar hacia la costa ecuatoriana, 4 de cada 10 prefieren la visita hacia las playas, 3 de cada 10 eligen recorridos por parajes rurales de la sierra, a 1 de cada 10 le gusta las prácticas turísticas en la Amazonía y a 2 de cada 10 les es indiferente el lugar de visita, mientras sean destinos bioseguros. El 40\% de los turistas tendrían estancias de al menos una noche; el 33\% pernoctaría entre 2 y 3 noches; el $9 \%$ tomaría una estancia más larga de más de 4 noches; y el $18 \%$ viajaría de ida por vuelta (excursión) a sitios cercanos del radio de su residencia (Mintur 2020).

El turista ha incrementado la búsqueda de servicios por internet, en especial el que reside en el área urbana. La crisis de la pandemia ha convertido a las personas en más indagadoras, y en muchos casos genera contenidos o comparte información de sus gustos y preferencias por los amplios canales de las redes sociales, según la Organización Panamericana de la Salud [OPS] (2020), que considera que "si antes de las medidas de aislamiento social era común observar a las personas en cualquier momento con su atención enfocada en la pantalla de sus smartphones, desde el inicio del aislamiento este hábito aumentó considerablemente". El nuevo turista es un gran inter- 
nauta, o al menos maneja de mejor manera la tecnología en segmentos de edades más avanzadas, eso hace que la toma de decisiones para su movilidad sea motivada por comentarios y por la visualización de contenidos creados para los diferentes targets de mercado.

\section{Discusión y conclusiones}

Los subsectores del turismo ecuatoriano han presentado diversos comportamientos: mientras alimentos y bebidas es el de mayor impacto negativo, sorprende que el número de empresas registradas en alojamiento, centros de turismo comunitario y operación e intermediación turística se hayan incrementado. Pese a que el sector alimentos y bebidas fue el que primero que obtuvo protocolos de bioseguridad y se adaptó a un nuevo modelo de servicio, es indudable que la baja en la demanda ocasionó muchas pérdidas y cierres de las empresas urbanas registradas en este rubro.

El turismo urbano en Ecuador atraviesa una crisis sin precedentes, no sólo por la pandemia, sino por la falta de efectividad de las medidas y políticas de reactivación. A esto se suma un año electoral, que aumenta la incertidumbre sobre su futuro pese a que los candidatos han coincido en anunciar medidas de ayuda. Un gran porcentaje de empresas han cerrado o están en la duda de reactivarse, especialmente el segmento urbano de bares, discotecas, eventos, agencias operadoras y alojamientos. Los repuntes han sido escasos y muy puntuales, especialmente alrededor de feriados nacionales, pero las adversidades en la gestión de los temas de salud han retrocedido todos los permisos operacionales alcanzados. Todo esto pese a que el sector cuenta con protocolos de bioseguridad y el país (junto con varias ciudades) tiene el sello de Safe Travel de la World Travel and Tourism Council. La incertidumbre continúa como el único factor que podría definir el futuro de las empresas turísticas del país en el entorno urbano.

En lo que se refiere al empleo, el turismo definitivamente fue uno de los sectores más golpeados en Ecuador, los índices para el mes de diciembre retrocedieron al turismo treinta años. Dentro de los sectores que componen esta actividad en Ecuador, la operación y el transporte turístico fueron los más golpeados, debido a que desde el inicio del confinamiento no tuvieron la oportunidad ni las condiciones para siquiera adaptarse como los restaurantes, por 
ejemplo, a un nuevo modelo de oferta. Esta experiencia así mismo desnudó claramente las debilidades del estado en materia turística: un Ministerio del ramo que no fue parte de la ayuda a los establecimientos turísticos, que no gestionó créditos blandos para los prestadores de servicios y que además evidenció una nula capacidad de respuesta ante este tipo de emergencias ha dejado serias dudas en su accionar dentro de la superestructura del turismo ecuatoriano.

La nueva demanda del turismo estará más preparada para la planificación del viaje; es por ello, que los actores clave del territorio receptor deben fortalecer a las prestaciones funcionales y simbológicas, aún más en el escenario de Covid-19. Las concentraciones en los principales atractivos turísticos de las ciudades dependerán de la evolución de la pandemia y de las restricciones locales. La tendencia del turismo de proximidad se ha incrementado, así que las zonas periféricas de las metrópolis y áreas rurales tendrán mayores oportunidades de recibir flujos turísticos. Ecuador ha incrementado los viajes internos, siendo las ciudades las emisoras de flujos turísticos; mientras tanto que la ruralidad va incrementando la llegada de visitantes. La decisión de viaje en la nueva demanda, está dada también por los protocolos de bioseguridad, si bien las pernoctaciones han disminuido, se observa el aumento de las preferencias hacia parajes rurales principalmente en compañía de grupos familiares y amigos; pero aún se mantiene el pensamiento de viajar hacia las zonas costeras del país, que habitualmente es uno de los escenarios masificadores del turismo.

Esta investigación ha sido la primera en obtener datos reales acerca del impacto del Covid-19 en el sector privado del turismo ecuatoriano, con base en herramientas metodológicas validadas para Ecuador y en especial para las áreas urbanas. Además, este estudio se apoya fuertemente en trabajos que los autores realizaron desde el segundo mes de confinamiento en Ecuador, con un seguimiento mensual hasta el mes de diciembre, por lo que los datos han tenido un tratamiento detallado y minucioso. Así mismo, el documento puede ser un aporte para el mismo sector privado, que a través de los gremios turísticos puede tener información más detallada de los sectores que necesitan un especial tratamiento de acuerdo al impacto que tuvieron durante el 2020. 
Sin embargo, la investigación también encontró limitaciones, especialmente en la recolección de datos de áreas urbanas localizadas en la Amazonía ecuatoriana. El trabajo abre nuevas posibilidades de profundizar y complementar este estudio con una investigación en las zonas rurales, consideradas satélites de las zonas urbanas y que dependen en buena parte de los flujos de estas últimas, lo que permitiría tener una visión más clara sobre un impacto regional.

\section{Referencias}

Canalis, X. (06 de mayo de 2009). Turismo de proximidad, una tendencia coyuntural que plantea un conflicto de intereses. Hosteltur. https:// www.hosteltur.com/60622_turismo-proximidad-tendencia-coyuntural-plantea-conflicto-intereses.html

Díaz-Soria, I. (noviembre, 2014). El turismo de proximidad: una nueva perspectiva de la movilidad turística. [Presentación de paper]. XIII Congreso ACEDIT, Benidorm, España. https://aecit.org/el-turismo-de-proximidad-una-nueva-perspectiva-de-la-movilidad-turis/ congress-papers/26/

Garrido, C. Cabanilla, E. Molina, E. Villagrán, P. (2021). Impacto del COVID-19 en el sector turístico ecuatoriano. Antecedentes, efectos, reflexiones y propuestas de recuperación. Universidad Internacional del Ecuador. Quito.

Ministerio de Turismo del Ecuador (MINTUR). (2020). Consolidado turístico nacional. Quito. MINTUR

Ministerio de Turismo del Ecuador (MINTUR). (2020b). Estudio del comportamiento del turismo nacional en el escenario COVID 19. Quito. MINTUR

Ministerio de Turismo del Ecuador (MINTUR). (2020c). Plan de Reactivación Turística. Quito. MINTUR.

Ministerio de Turismo del Ecuador (MINTUR). (2020d). Políticas de Reactivación del Turismo en el Ecuador. Quito. MINTUR.

Ministerio de Turismo del Ecuador (MINTUR). (2021). Revista Panorama Turístico. Cuarta Edición, Feb. 2021. Quito. MINTUR

Olcina J. (2020). Pandemia, cambio climático y turismo: acciones para lo inmediato y lo próximo; en Simancas Cruz M., Hernández Martín M. y Padrón Fumero N. (Coord.) Turismo pos - COVID - 19. Reflexiones, Retos y Oportunidades. 
Organización Mundial del Turismo (2019). Panorama OMT del turismo internacional, edición 2019. Recuperado de: https://www.e-unwto.org/ doi/pdf/10.18111/9789284421237

Organización Mundial del Turismo (2020a). El turismo mundial sigue paralizado mientras el 100\% de los países imponen restricciones a los viajes. Recuperado de: https://www.unwto.org/es/news/covid-19-turismo-mundial-sigue-paralizado-mientras-el-100-de-los-paises-imponen-restricciones-a-los-viajes

Organización Mundial del Turismo (2020b). Covid - 19 y Turismo. 2020: análisis del año. OMT.

Organización Panamericana de la Salud (OPS). (2020). Las redes sociales y COVID-19: la contribución de BIREME. OPS. https://www. paho.org/bireme/index.php?option $=$ com_content\&view $=$ article\&i$\mathrm{d}=479$ :redes-sociais-e-covid-19-a-contribuicao-da-bireme\&Itemi$\mathrm{d}=183$ \&lang=es

Smart Travel. (2020). Observatur: 10 grandes tendencias en el escenario post COVID-19. Smart Travel. https://www.smarttravel.news/observatur-10-grandes-tendencias-escenario-post-covid-19/ 